\title{
WHOOPING CRANES NESTING IN ALBERTA
}

BRIAN JOHNS, Canadian Wildlife Service, 115 Perimeter Road, Saskatoon, SK S7N OX4

On an early spring day in 1977 Ernie Kuyt, of the Canadian Wildlife Service, discovered the last Whooping Crane nest of the season. This "last nest" would prove to be the first nest discovered in Alberta in 63 years. ${ }^{4}$ Twenty years later this pair's Composite Nesting Area (CNA)(the CNA incorporates the nesting sites of a particular pair and approximates the territory the pair uses during the raising of young) ${ }^{5}$ is still occupied by a pair of unbanded cranes. Being unbanded, it is not possible to tell if the cranes occupying the territory today are the original pair or if any mate changes have taken place or whether they are entirely new birds. The Alberta breeding area has expanded both west and south of the original site and in 1997 contained eight breeding pairs (Fig. 1). ${ }^{3}$ Highlights of the breeding history of these Alberta cranes are:

A single nesting pair has bred in the territory of the original nesting pair for 20 of the last 21 years, skipping only 1980. This territory has been designated as CNA A-1. The cranes breeding here have produced seven offspring that have survived long enough to arrive on the wintering grounds at the Aransas National Wildlife Refuge on the Texas gulf coast.

During 1997 this pair's nest (2/97) was discovered on 7 May with two eggs. The pair had one chick and one egg on the morning of 6 June. They were observed again on June 16 with a single chick and were last seen on 11 August with a single chick. It is unknown whether they have safely arrived on the wintering grounds.
In 1988 a second pair took up residence in Alberta (CNA A-2). Both birds were banded. The female (banded Blue White spiral-Blue White spiral) was shot in Texas in January 1989 after successfully raising a banded chick on their first nesting attempt. The male (blue/ blue-Yellow) repaired with another banded bird (Yellow-Red) and nested in 1990. The male disappeared during the winter of 1992-93 and the female was seen with an unbanded bird that winter and the following nesting season. There was no nest in 1994. In 1995 the female was observed with a new mate banded Yellow-Yellow/black/Yellow (see below). Nest 15/97 was discovered 16 May and had hatched two chicks by 9 June. One chick was missing the morning of 25 June. The pair with its remaining chick was last seen in Wood Buffalo National Park on 11 August. The family group was observed on the wintering grounds on 6 November with its single chick.

In 1990 a pair of banded birds (male banded Yellow-Yellow/black/ Yellow and female banded WhiteYellow/black/Yellow) nested together, but then separated and nested elsewhere with different mates in following years (YellowYellow/black/Yellow moves to CNA A-2 in 1995).

In 1992 a pair of unbanded cranes nested in CNA A-4. This pair hatched a chick on their first two breeding attempts, failed to show up on their territory in 1994 and then a pair of unbanded cranes has nested unsuccessfully each year since. In 1997 this pair's nest (4/97) was discovered on 7 May. The nest was not 


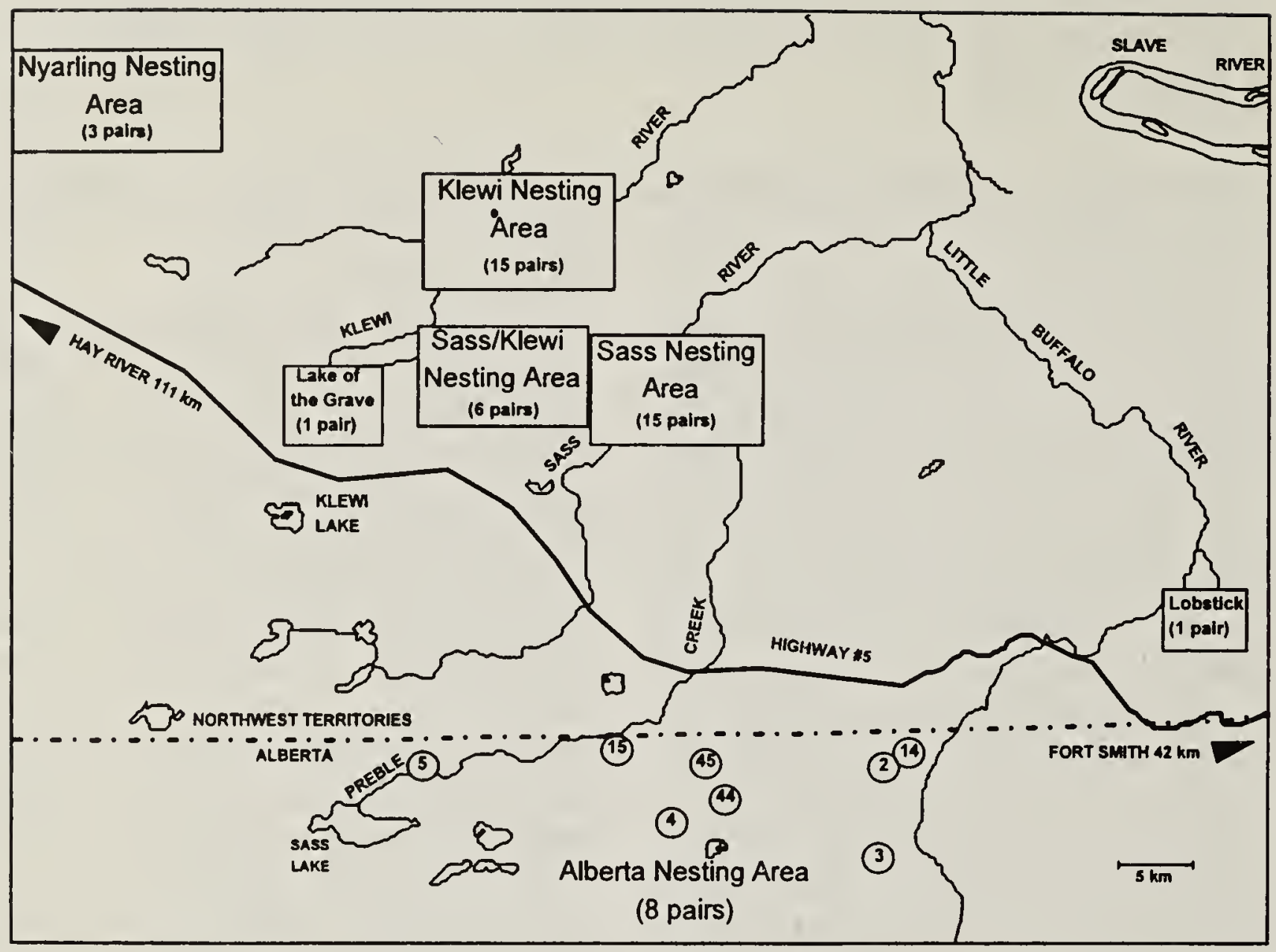

(3) Alberta nest number.

Figure 1. Whooping Crane nesting areas, Wood Buffalo National Park, 1997.

rechecked until 23 May when neither the pair nor their nest could be relocated. The pair was not seen again during the remainder of the summer.

Beginning in 1993 a new pair began nesting (CNA A-5) south of the original Alberta pair. This pair (male banded Green/white/Green-Yellow/ black/Yellow and an unbanded female) has never brought a chick to Aransas, their chicks have usually been lost shortly after hatching. In 1997 this pair, nesting at nest $3 / 97$, hatched two chicks between the mornings of 4 and 6 June. One of the chicks went missing on 13 June and the remaining chick was last seen in Wood Buffalo National Park 16 August with its parents. The adults were seen in North Dakota on 14 October without a chick and arrived on the wintering grounds alone in late October.

A new pair (male Yellow/black/ Yellow-Yellow/black/Yellow and fe- male Green-Yellow/black/Yellow) was discovered in 1993 along Preble Creek, west of the traditional nesting area. They skipped the 1994 nesting season but have nested each year since (CNA A-6). Their 1997 nest (5/97) was discovered 7 May and hatched two chicks by 3 June. One of the chicks went missing between the evening of 10 June and the morning of 11 June. The pair was seen with a single chick on $11 \mathrm{Au}$ gust but when they arrived on the wintering grounds on 25 November, they were without the chick.

In 1995 a pair of unbanded cranes established a territory adjacent to the original CNA A-1 and have nested within 425-450 metres of the original pair each year since. This new territory has been designated as CNA A-7. In 1997 the pair nested at nest 14/97. The nest contained two eggs and at least one chick was hatched. The pair with its single 
chick was last observed on $11 \mathrm{Au}-$ gust. Being unbanded, the specific wintering site of these cranes hasn't been determined yet and it is not known if their chick survived.

Two additional pairs of unbanded birds nested for the first time in 1997 at nests $44 / 97$ and $45 / 97$. Nest 44/97 hatched two chicks between 2 and 4 June and lost one between the mornings of 13 and 15 June. The remaining chick was last seen $24 \mathrm{Au}$ gust. Nest 45/97 was discovered 2 June and the cranes were still incubating 2 July. The nest was abandoned on 4 July and the eggs were predated by the time they were collected on 9 July. Being new nesting pairs the CNA numbers have yet to be designated for nests 44/97 and $45 / 97$. Wintering areas for these two pairs are also not yet determined so it is unknown whether the young from nest $44 / 97$ safely arrived on the wintering grounds.

As noted above, pairs from CNA's $A-2, A-4$ and $A-6$ did not nest in 1994. There were also 13 other experienced breeding pairs that failed to nest in $1994 .^{2}$ Information available from studies conducted on the Texas wintering grounds ${ }^{1,6}$ indicates that blue crab numbers, the principal winter food of the cranes, were very low throughout most of the winter of 1993/94. The cranes exhibited a net energy loss ${ }^{1}$ and many were likely in poor physical condition prior to the breeding season. This was reflected during the spring migration, which was very erratic with some birds leaving Aransas earlier than usual while others left later than normal, three cranes eventually summered at Aransas. ${ }^{7}$ Spring arrivals to the breeding grounds in Wood Buffalo National Park that year were also erratic. Several breeding pairs arrived a week or more later than usual with one pair arriving three weeks later than expected. ${ }^{2}$
Nesting habitat in the Alberta portion of Wood Buffalo National Park appears adequate to support additional breeding pairs ${ }^{4}$ as evidenced by the expansion of Whooping Cranes into this important new breeding area. However, continued expansion of the breeding grounds may be regulated by conditions on the wintering area $4000 \mathrm{~km}$ to the south.

I would like to thank E. Kuyt for introducing me to the Whooping Crane breeding area, Doug Bergeson and other current and past staff from Wood Buffalo National Park for their cooperation and Big River Air Ltd. of Fort Smith.

1. CHAVEZ-RAMIREZ, F. 1997. Food and energy intake rates of wintering Whooping Cranes foraging on two selected food items. Proceedings of the 7th North American Crane Workshop. Biloxi, Mississippi.

2. JOHNS, B. 1994. Whooping crane breeding pair surveys 1-29 May, 1994. Canadian Wildlife Service Unpublished Report. 31 pp.

3. 1997. Whooping Cranes in Wood Buffalo National Park, 1997. Canadian Wildlife Service Unpublished Report.

4. KUYT, E. 1978. A modern nesting record for Whooping Cranes in Alberta. Blue Jay 36:147-148.

5. - 1981. Population status, nest site fidelity and breeding habitat of Whooping Cranes. Pages 119-125 in Lewis, J.C. and H. Masatomi (eds.), Crane Research Around the World: Proceedings of the International Crane Symposium, Sapporo, Japan.

6. STEHN, T.V. 1994. Whooping Cranes during the 1993-94 winter. U.S. Fish and Wildlife Service Unpublished Report. $52 \mathrm{pp}$.

7. 1 1995. Whooping Cranes during the 1994-95 winter. U.S. Fish and Wildlife Service Unpublished Report. $42 \mathrm{pp}$. 